Gut, 1965, 6, 387

\title{
Glucose and fructose absorption in idiopathic steatorrhoea
}

\author{
C. D. HOLDSWORTH AND A. M. DAWSON
}

From the Department of Medicine, Royal Free Hospital, London

EDITORIAL SYNOPSIS The test described appears to be the most sensitive available assessment of jejunal function. It seems likely that the impairment of absorption in idiopathic steatorrhoea is largely due to diminished mucosal surface area.

Although a flat glucose tolerance test has long been regarded as one of the hallmarks of idiopathic steatorrhoea (Thaysen, 1926), there have been only a few attempts to measure glucose absorption more directly in this condition. On the few occasions on which this has been done, by using intestinal intubation, glucose absorption has been found to be only a fraction of that in normal persons (Groen, 1938; Fordtran, Levitan, Bickerman, Burrows, and Ingelfinger, 1961; Schedl and Clifton, 1961) but not to correlate with the degree of flattening of the glucose tolerance curves on the same patients (Taylor and Wightman, 1952).

Fructose absorption has not been directly studied in idiopathic steatorrhoea, although it has been claimed on the basis of blood tolerance tests that fructose absorption is unaffected, while glucose absorption is defective (Maegraith, Adams, Havard, King, and Millet, 1945).

In this paper the results are reported of a study of glucose, fructose, and water absorption from the jejunum of patients with idiopathic steatorrhoea, and these are compared with those found using an identical perfusion technique in normal subjects (Holdsworth and Dawson, 1964). The findings before and after treatment with a gluten-free diet are discussed in relation to the clinical response of these patients, the appearance of jejunal biopsies, and standard tests of small intestinal function.

\section{METHODS}

PERFUSION TECHNIQUE Glucose and fructose absorption was studied by a perfusion technique described previously (Holdsworth and Dawson, 1964), which is modified from a method described by Schedl and Clifton (1961). A double-lumen polyvinyl tube is introduced into the upper jejunum, and a known concentration of sugar, made isotonic by adding an appropriate amount of sodium chloride, is pumped into the jejunum at a constant flow rate of $20 \mathrm{ml} . / \mathrm{min}$. through a hole in one lumen immediately distal to the duodeno-jejunal flexure (Fig. 1). After perfusing the intestine for 30 minutes a steady state is reached, and intraluminal contents are then aspirated through a hole in the other lumen of the tube $30 \mathrm{~cm}$. beyond the proximal hole. Net water absorption is determined by use of the non-absorbable marker poly-
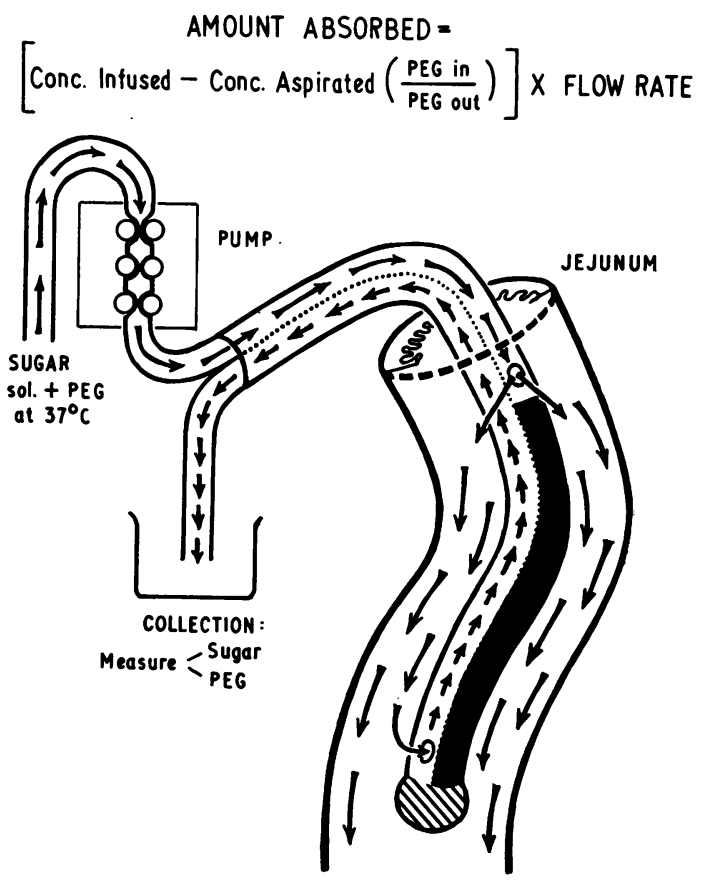

FIG. 1. Diagram of the method for studying absorption of water-soluble substances from the jejunum in men. 
TABLE I

DISCREPANCY IN GLUCOSE ABSORPTION RATE MEASURED IN SUCCESSIVE 10-MINUTE SAMPLES AFTER A 30-MINUTE EQUILIBRATION PERIOD IN NORMAL SUBJECTS AND IN PATIENTS WITH IDIOPATHIC STEATORRHOEA

\begin{tabular}{|c|c|c|c|c|c|c|c|c|c|c|}
\hline \multirow{6}{*}{$\begin{array}{l}\text { Concentration infused } \\
\text { (g./100 ml.) } \\
\text { Number of experiments } \\
\text { Mean absorption (M.) } \\
\text { (g./30 cm./min.) } \\
\text { Mean discrepancy in } \\
\text { results between } \\
\text { successive samples (x) } \\
\text { (g./30 cm./min.) } \\
\% \text { discrepancy }\end{array}$} & \multicolumn{5}{|c|}{ Normal } & \multicolumn{5}{|c|}{ Idiopathic Steatorrhoea } \\
\hline & 0.5 & $1 \cdot 0$ & $2 \cdot 5$ & $4 \cdot 3$ & $5 \cdot 0$ & 0.5 & $1 \cdot 0$ & $2 \cdot 5$ & $4 \cdot 3$ & $5 \cdot 0$ \\
\hline & 8 & & & 7 & 11 & & & 7 & 7 & \\
\hline & 0.076 & 0.135 & $0 \cdot 28$ & 0.364 & 0.39 & 0.0124 & 0.021 & 0.09 & $0 \cdot 116$ & $0 \cdot 102$ \\
\hline & 0.007 & 0.016 & 0.014 & 0.053 & 0.045 & 0.005 & 0.013 & 0.03 & 0.04 & 0.05 \\
\hline & $6 \cdot 3$ & $8 \cdot 7$ & $8 \cdot 5$ & $14 \cdot 5$ & $11 \cdot 5$ & 40 & 62 & 30 & 35 & 49 \\
\hline
\end{tabular}

ethylene glycol, which is included in the infused solution at a concentration of $0.5 \mathrm{~g} . / 100 \mathrm{ml}$. Determination of the concentration of polyethylene glycol and of sugar in the aspirated fluid enables the actual amount of sugar absorbed to be calculated using the formula indicated in Figure 1.

In each patient studied, glucose and fructose absorption was studied from varying concentrations of sugar, so that an indication of the kinetics of the process involved could be obtained. For each concentration infused, two successive 10-minute samples were collected for analysis after the equilibration period, and the mean of the absorption rate in these periods was used in calculating the final results. There was often a discrepancy between the absorption rates calculated in the two collection periods, and the mean discrepancy found in all perfusions using glucose solutions is shown in Table $I$, where it is compared with similar data from perfusions in normal subjects. The actual discrepancy at each concentration is very similar in normal subjects and patients with idiopathic steatorrhoea. Due to the smaller amount absorbed, however, this results in a much greater percentage variation in subjects with idiopathic steatorrhoea. Very similar results were obtained when fructose absorption was studied. This method cannot therefore be used to determine minor changes in absorption in this condition, but in practice the changes found either as variation from normal, or improvement with treatment, were much greater than the possible error involved.

CHEMICAL METHODS Polyethylene glycol was determined by the method of Hydén (1956). Glucose and fructose were determined on the Technicon AutoAnalyzer using a method based on the reduction of potassium ferricyanide (Hoffman, 1937).

PATIENTS STUDIED Kinetic studies of glucose and fructose absorption were carried out on 10 occasions in six patients with idiopathic steatorrhoea. In seven of these perfusion studies, the condition was in relapse, due either to no previous treatment (six cases) or failure to adhere to a diet (one case). The test was repeated after dietary treatment in four cases.

All the patients had only recently been diagnosed, the criteria for the diagnosis being clinical and biochemical evidence of malabsorption, for example, megaloblastic anaemia, steatorrhoea, or osteomalacia, and in each case a jejunal biopsy, obtained by a Crosby capsule (Crosby and Kugler, 1957) which showed stunted or absent villi. The mean daily faecal fat excretion over at least a six-day period on the normal ward diet was determined (van de Kamer, ten Bokkel Huinink, and Weyers, 1949), the upper limit of normal in this laboratory being $5.5 \mathrm{~g}$. daily (2.9 \pm 2.5 mean \pm 2 S.D.). The xylose tolerance test was carried out as described by Christiansen, Kirsner, and Ablaza (1959) using a $25 \mathrm{~g}$. dose, and collecting urine for five hours. An excretion of $4 \cdot 2 \mathrm{~g}$. was taken as the lower limit of the normal, and one blood level of xylose at one and a half hours after the oral dose was measured as a check on renal function, being greater than $35 \mathrm{mg}$./ $100 \mathrm{ml}$. in cases with normal absorption.

\section{RESULTS}

MEAN GLUCOSE AND FRUCTOSE ABSORPTION The mean results of the glucose and fructose perfusion tests in the proximal jejunum of patients with idiopathic steatorrhoea in relapse are shown in Figure 2. As would be expected, the absorption of both monosaccharides is depressed, the extent of this depression varying from $60 \%$ (fructose perfused at a concentration of $2.5 \%$ and $5 \%$ ) to $80 \%$ (glucose perfused at a concentration of $0.5 \%$ and $1.0 \%$ ).

In normal subjects, the absorption of glucose under these conditions approaches a maximum, and in fact follows Michaelis-Menten kinetics, suggesting saturation of a special transport system, whereas fructose absorption bears a linear relationship to the concentration infused (Holdsworth and Dawson, 1964). The differing kinetics of the two sugars would appear to be maintained in idiopathic steatorrhoea, as glucose absorption does not change significantly as the infused glucose concentration is increased from $2.5 \mathrm{~g} . / 100 \mathrm{ml}$. to $5.0 \mathrm{~g} . / 100 \mathrm{ml}$. On the other hand, fructose absorption doubles over the same range. In spite of the wide individual scatter, reflected by the large standard error, this increase is 


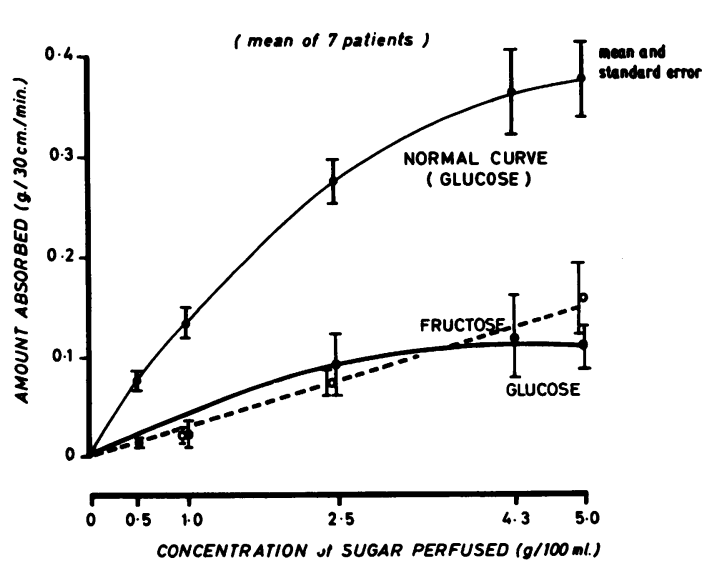

FIG. 2. Absorption of glucose and fructose from jejunum in patients with idiopathic steatorrhoea compared with normal subjects (mean \pm S.E.M.).

statistically significant when the rise in individual patients is assessed by a paired $t$ test $(p<0.05)$.

The observation that fructose is absorbed more efficiently than glucose when perfused at a concentration of $5.0 \mathrm{~g} . / 100 \mathrm{ml}$. is not statistically significant.

MEAN WATER ABSORPTION Mean net water absorption in the seven patients with idiopathic steatorrhoea in relapse is shown in Figure 3. At no concentration of either sugar is there net water absorption; indeed there is a tendency for net water secretion into the lumen, in spite of significant monosaccharide absorption from the same solutions. At all concentrations the net water absorption is not significantly different from zero, in marked contrast

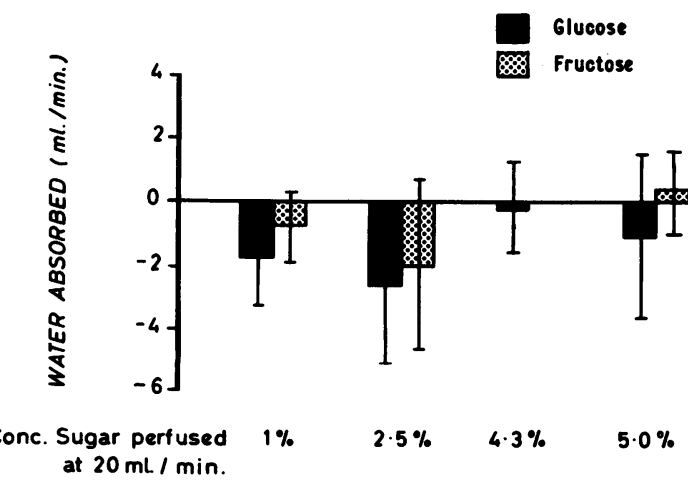

FIG. 3. Net water movement in jejunum of patients with idiopathic steatorrhoea during perfusion of glucose and fructose solutions: + represents net water absorption; - represents net water secretion (mean \pm S.E.M.). to the findings in normal subjects (Holdsworth and Dawson, 1964).

EFFECT OF GLUTEN-FREE DIET ON MONOSACCHARIDE ABSORPTION The results shown in Table II enable comparisons to be drawn between glucose, fructose, and water absorption and other tests of small intestinal function, biopsy findings, and clinical response.

Patient 1 , who was a young man with only a oneyear history of diarrhoea, had an excellent clinical response to a gluten-free diet. All absorption tests reverted to normal, including his glucose absorption and water absorption. Before treatment examination of the small gut mucosa with the dissecting microscope showed complete absence of villi, and histologically the gross abnormality was confirmed. After treatment the abnormal broadening of the lamina propria had disappeared, and the villi were only slightly more stunted and broader than normal.

Patient 2 failed for social reasons to adhere strictly to a gluten-free régime. His jejunal mucosa did not improve, and glucose absorption remained subnormal.

Patient 3, who has been reported in more detail elsewhere (Dawson, Holdsworth, and Pitcher, 1964), made an excellent clinical recovery, and her xylose test and faecal fat excretion indicated normal absorption. Jejunal biopsy, however, revealed considerable residual abnormality in the jejunum and this was reflected by grossly defective glucose absorption.

Grossly defective glucose absorption was also seen in patients 4,5 , and 6 before treatment. At this time all three patients had steatorrhoea and suffered from varying degrees of diarrhoea and nutritional disturbances. Jejunal biopsies from each patient showed complete absence of villi when examined under the dissecting microscope. Patient 4 had a good clinical response, and a considerable improvement in his jejunal biopsy. Although faecal fat excretion and xylose absorption were quite normal after treatment, glucose absorption only improved to the lower limit of normal. Patient 5 still had defective glucose absorption after treatment, and mild steatorrhoea and impairment of xylose absorption also persisted. Patient 6 , whose main disability was an anaemia due to folic acid deficiency, had grossly defective glucose and water absorption in the jejunum although the xylose absorption test gave normal results. In this patient the study was not repeated after treatment.

Of the five patients in whom glucose absorption was studied after dietary treatment, therefore, it was normal in one, at the lower limit of normal in one, and definitely still abnormal in three. Changes in 
TABLE II

TESTS OF ABSORPTION AND NUTRITIONAL STATUS IN SIX PATIENTS WITH IDIOPATHIC STEATORRHOEA

\begin{tabular}{|c|c|c|c|c|c|c|c|c|}
\hline Patient & $\begin{array}{l}\text { Gluten-free } \\
\text { Diet }\end{array}$ & $\begin{array}{l}\text { Weight } \\
\text { (lb.) }\end{array}$ & $\begin{array}{l}\text { Faecal } \\
\text { Fat } \\
\text { (g./24 } \\
\text { hr.) }\end{array}$ & $\begin{array}{l}\text { Xylose } \\
\text { Excretion } \\
(g .15 \text { hr. })\end{array}$ & $\begin{array}{l}\text { Glucose Absorption }{ }^{1} \\
\text { (normal range } 0.2 \text { to } \\
0.5 \mathrm{~g} . / 30 \mathrm{~cm} . / \mathrm{min} .)\end{array}$ & $\begin{array}{l}\text { Water Absorption } 1 \\
\text { (normal range } 2 \text { to } \\
7 \mathrm{ml} . / \mathrm{min} . / 30 \mathrm{~cm} .)\end{array}$ & Jejunal Biopsy & $\begin{array}{l}\text { Clinical } \\
\text { Response }\end{array}$ \\
\hline 1 K.L.P. & $\begin{array}{l}\text { Before } \\
\text { After } 6 \mathrm{mth} \text {. }\end{array}$ & $\begin{array}{l}137 \\
179\end{array}$ & $\begin{array}{l}20 \\
4 \cdot 5\end{array}$ & $\begin{array}{l}2 \cdot 8 \\
6 \cdot 7\end{array}$ & $\begin{array}{l}0 \cdot 1 \\
0 \cdot 32\end{array}$ & $\begin{array}{l}-7 \\
+4\end{array}$ & $\begin{array}{l}\text { Flat } \\
\text { Mild } \\
\text { abnormality } \\
\text { only }\end{array}$ & Excellent \\
\hline 2 K.P. & 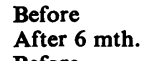 & $\begin{array}{r}114 \\
109\end{array}$ & $\begin{array}{l}13 \\
15\end{array}$ & $\begin{array}{l}2 \cdot 0 \\
1.0\end{array}$ & $\begin{array}{l}0.05 \\
0.15\end{array}$ & $\begin{array}{l}-2 \\
+2 \cdot 5\end{array}$ & Flat & $\begin{array}{l}\text { None (diet } \\
\text { failure) }\end{array}$ \\
\hline 3 G.T. & $\begin{array}{l}\text { Before } \\
\text { After } 6 \mathrm{mth} \text {. }\end{array}$ & $\begin{array}{r}56 \\
115\end{array}$ & $\begin{array}{l}7 \\
2 \cdot 6\end{array}$ & $\begin{array}{l}0.5 \\
6.8\end{array}$ & $\overline{0.05}$ & -4 & $\begin{array}{l}\text { Flat } \\
\text { Flat } \\
\text { Subtotal } \\
\text { villous } \\
\text { atrophy }\end{array}$ & $\begin{array}{l}\text { railure) } \\
\text { Excellent }\end{array}$ \\
\hline 4 R.M. & $\begin{array}{l}\text { Before } \\
\text { After } 6 \mathrm{mth} \text {. }\end{array}$ & $\begin{array}{l}151 \\
172\end{array}$ & $\begin{array}{l}15 \\
4 \cdot 5\end{array}$ & $\begin{array}{l}1 \cdot 9 \\
6\end{array}$ & $\begin{array}{l}0.04 \\
0.2\end{array}$ & $\begin{array}{l}-1 \\
+2 \cdot 5\end{array}$ & $\begin{array}{l}\text { Flat } \\
\text { Subtotal } \\
\text { villous } \\
\text { atrophy }\end{array}$ & Good \\
\hline $\begin{array}{l}6 \text { Q.S. } \\
{ }^{1} \text { Calculate }\end{array}$ & $\begin{array}{l}\text { Before } \\
\text { as mean abso }\end{array}$ & $\begin{array}{l}90 \\
\text { tion frc }\end{array}$ & $\begin{array}{l}7 \cdot 1 \\
\text { solutic }\end{array}$ & $\begin{array}{l}4.0 \\
\text { of } 4.3 \mathrm{~g}\end{array}$ & $\begin{array}{c}0.035 \\
\text { ml. and } 5.0 \mathrm{~g} . / 100\end{array}$ & $\begin{array}{l}-2 \cdot 5 \\
\text { ncentrations }\end{array}$ & Flat & \\
\hline
\end{tabular}

water absorption paralleled closely changes in glucose absorption, and only returned completely to normal in patient 1 .

\section{DISCUSSION}

The reproducibility of the perfusion technique used in these studies is not so good in patients with idiopathic steatorrhoea as in normal subjects. In spite of this, it is probably the best technique available at the moment for the direct study of absorption of water-soluble materials such as sugars.

Schedl and Clifton (1961) studied the kinetics of glucose absorption in two patients with idiopathic steatorrhoea, and from their report, which was only in abstract form, it would appear that they also found that it followed saturation kinetics. Absent or defective water absorption in the jejunum of patients with idiopathic steatorrhoea (Fordtran et al., 1961) and also in children with coeliac disease (Borgstrom, Lindquist, and Lundh, 1961) has been reported previously. To compensate for this, there is a greater net water absorption in the ileum of these patients than in normal subjects (Schedl and Clifton, 1963).

In this condition there are two factors which could possibly account for the diminished absorption. The most obvious is the diminished mucosal surface area due to the absence of villi, but in addition the columnar absorbing cells are abnormal and it seemed a possibility that the special transport system for certain sugars might be damaged. The fact that the absorption of glucose retains saturation kinetics suggests that the diminished mucosal surface area is the more important factor; inspection of biopsies under the dissecting microscope reveals that this diminution could be quite an adequate explanation. Indeed, it is surprising in a jejunum as severely damaged as that of, for example, case 1 or 2 , that glucose is absorbed as well as was demonstrated.

The relative degree of impairment of glucose and fructose absorption in idiopathic steatorrhoea is of some interest in view of the suggestions that fructose absorption is the less severely affected by sprue (Maegraith et al., 1945). Although we appeared to confirm this, the results in fact are not significant statistically. Because of the poor reproducibility of this test in idiopathic steatorrhoea, many more experiments would be necessary to settle this question.

Absorption of glucose and water when assessed by this technique appears to be the most sensitive test of jejunal function which is available, and never reverted to normal if any of the other tests showed persistent abnormalities. It is noteworthy that glucose absorption can be severely depressed in the jejunum of patients with idiopathic steatorrhoea at a time when the standard $25 \mathrm{~g}$. xylose absorption test indicates normal function (patients 3 and 6). This may be due to the fact that the absorption studied with the perfusion method is confined to the part of the jejunum which is most severely affected by the disease, and which is the last part to improve histologically. The standard tests of absorption function, including measurement of faecal fat excretion and xylose absorption, are relatively crude due to the large reserve capacity for their absorption 
in the normal small bowel. In general, they measure the absorptive capacity of the small bowel as a whole.

\section{SUMMARY}

By studying the absorption of glucose and fructose in the upper jejunum of patients with idiopathic steatorrhoea, it was possible to demonstrate that the different kinetics of absorption of these sugars seen in normal subjects still obtain. This suggests that the impairment of absorption is largely due to the diminished mucosal surface area in this condition. It was confirmed that there is a tendency for net accumulation of fluid to occur in the jejunum of patients with this disease, even when glucose is being absorbed to a significant extent. Glucose absorption measured by the perfusion technique was capable of revealing persisting functional abnormality in the upper jejunum after other absorption tests, such as the standard xylose absorption method, which assess the function of the small intestine as a whole, had returned to normal.

\section{REFERENCES}

Borgstrom, B., Lindquist, B., and Lundh, G. (1961). Digestive studies in children. Amer. J. dis. Child., 101, 454-466.
Christiansen, P. A., Kirsner, J. B., and Ablaza, J. (1959). D-xylose and its use in the diagnosis of malabsorptive states. Amer. $J$. Med., 27, 443-453.

Crosby, W. H., and Kugler, H. G. (1957). Intraluminal biopsy of the small intestine: the intestinal biopsy capsule. Amer. J. dig. Dis., 2, 236-241.

Dawson, A. M., Holdsworth, C. D., and Pitcher, C. S. (1964). Sideroblastic anaemia in adult coeliac disease. Gut, 5, 304-308.

Fordtran, J. S., Levitan, R., Bickerman, V., Burrows, B. A., and Ingelfinger, F. J. (1961). The kinetics of water absorption in the human intestine. Trans. Ass. Amer. Phycns., 74, 195-206.

Groen, J. (1938). The absorption of glucose from the small intestine in deficiency disease. New Engl. J. Med., 218, 247-253.

Hoffman, W. S. (1937). A rapid photoelectric method for the determination of glucose in blood and urine. J. biol., Chem., 120, 51-55.

Holdsworth, C. D., and Dawson, A. M. (1964). The absorption of monosaccharides in man. Clin. Sci., 27, 371-379.

Hydén, S. (1956). A turbidimetric method for the determination of higher polyethylene glycols in biological materials. $K$. Lantbr. Högsk. Annlr., 22, 139-145.

van de Kamer, J. H., ten Bokkel Huinink, H., and Weyers, H. A. (1949). Rapid method for the determination of fat in faeces. J. biol. Chem., 177, 347-355.

Maegraith, B. G., Adams, A. R. D., Havard, R. E., King, J. D., and Millet, R. F. (1945). Carbohydrate absorption in sprue. Lancet, 2,635 .

Schedl, H. P., and Clifton, J. A. (1961). Kinetics of intestinal absorption in man: normal subjects and patients with sprue. J. clin. Invest., 40, 1079-1080.

intestine. Nature (Lond.), 199, 1264-1267.

Taylor, R. M., and Wightman, K. J. R. (1952). Glucose absorption from the duodenum in patients with steatorrhea. Amer. J. med. Sci., 224, 190-193.

Thaysen, T. E. H. (1926). Uber Fettdiarrhöen. Acta. med. Scand., 64, 292-400. 